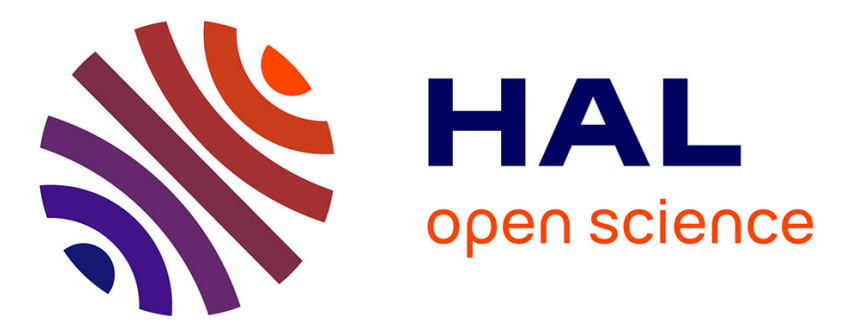

\title{
Grafting of phosphorus flame retardants on flax fabrics: Comparison between two routes
}

Raymond Hajj, Roland El Hage, Rodolphe Sonnier, Belkacem Otazaghine, Benjamin Gallard, Sophie Rouif, Michel Nakhl, José-Marie Lopez-Cuesta

\section{- To cite this version:}

Raymond Hajj, Roland El Hage, Rodolphe Sonnier, Belkacem Otazaghine, Benjamin Gallard, et al.. Grafting of phosphorus flame retardants on flax fabrics: Comparison between two routes. Polymer Degradation and Stability, 2018, 147, pp.25-34. 10.1016/j.polymdegradstab.2017.11.006 . hal02874840

\section{HAL Id: hal-02874840 \\ https://hal.science/hal-02874840}

Submitted on 26 May 2021

HAL is a multi-disciplinary open access archive for the deposit and dissemination of scientific research documents, whether they are published or not. The documents may come from teaching and research institutions in France or abroad, or from public or private research centers.
L'archive ouverte pluridisciplinaire HAL, est destinée au dépôt et à la diffusion de documents scientifiques de niveau recherche, publiés ou non, émanant des établissements d'enseignement et de recherche français ou étrangers, des laboratoires publics ou privés. 


\title{
Grafting of phosphorus flame retardants on flax fabrics: Comparison between two routes
}

\author{
Raymond Hajj $^{\mathrm{a}, \mathrm{b}, \mathrm{c}}$, Roland El Hage ${ }^{\mathrm{a}, \mathrm{c}, * *}$, Rodolphe Sonnier ${ }^{\mathrm{b}, *}$, Belkacem Otazaghine ${ }^{\mathrm{b}}$, \\ Benjamin Gallard $^{\mathrm{b}}$, Sophie Rouif ${ }^{\mathrm{d}}$, Michel Nakhl ${ }^{\mathrm{a}, \mathrm{c}}$, José-Marie Lopez-Cuesta ${ }^{\mathrm{b}}$
}

a LCPM, Faculty of Sciences, Lebanese University, Fanar, Lebanon

b C2MA, Ecole des Mines d'Alès/Institut Mines Telecom, 6, avenue de Clavières, 30100 Alès, France

${ }^{\mathrm{c}}$ Plateforme de Recherche en Nanosciences et Nanotechnologies, Lebanese University, EDST, Lebanon

' Ionisos SA, Dagneux, France

\section{A B S T R A C T}

Flax fabrics were modified through two grafting methods in order to improve their flame retardancy. Vinyl phosphonic acid was used to treat flax fabrics via a condensation reaction between phosphonic acid function and flax hydroxyl groups. It was also grafted under radiation conditions taking advantage of its carbon-carbon double bond. Grafting efficiency of each method was assessed by X-ray fluorescence and scanning electron microscopy. The effect of the phosphorus grafting on fire behavior was studied using thermogravimetric analysis, pyrolysis combustion flow calorimetry and a preliminary fire test. In all cases, the diffusion of the phosphorus molecules into the elementary fibers bulk was observed. Phosphorus content reached $1.4 \mathrm{wt} \%$ using radiation grafting, leading to self-extinguishing fabrics.

Keywords:

Flame retardancy

Flax

Phosphorus

Grafting

Chemical modification

E-beam irradiation

\section{Introduction}

Natural fabrics (especially cotton and flax) have been used in textile industry for centuries. Moreover natural fibers are getting more importance in composites as a substitute for glass, carbon, or aramid fibers $[1,2]$. Natural fibers have many attractive advantages as: renewability, biodegradability, good availability, low cost, low density, non-toxicity, low abrasiveness (compared to fiberglass) and good mechanical properties [3-5]. Moreover, fibers modification is possible in order to overcome some disadvantages [6-10] such as: thermal, moisture, flammability, and ultraviolet rays sensitivities.

It has been reported that natural fibers can be modified by various treatments $[2,6,8,9,11-15]$ with or without chemical coupling. Many methods have been investigated such as gamma or electron beam irradiation [16-18], UV irradiation [19], corona [19,20], plasma [21], silane treatment [12], alkaline treatment [22,23] and acetylation [24] in order to achieve chemical coupling after absorption or adsorption of flame retardants (FRs).

The researchers have focalized their interests to phosphorus-containing FRs since halogen-containing FRs have some environmental concerns as releasing toxic gases during burning $[11,25]$. Phosphoruscontaining flame retardants can act in condensed or vapor phases
$[25,26]$. Numerous studies have been reported in the literature about the flame retardancy of lignocellulosic materials modified with phosphorus compounds for textile or composite applications [27-34]. Phosphorus presence usually leads to a decrease in thermal stability but promotes charring by dehydration of cellulose [35]. Among various phosphorus flame retardants, VPA (vinyl phosphonic acid) has already been used to enhance flame retardancy of textiles including cotton. Opwis et al. have grafted VPA on cotton using photopolymerization in presence of a crosslinking agent and a photo-initiator [35]. They used 50 vol\% of VPA dissolved in ethanol. Fabrics were wetted in FR solution and then irradiated by UV rays. Results showed that $2 \%$ of phosphorus were grafted on the cotton textile which showed a high level of flame retardant performance (self-extinguishment). Gashti et al. [36] have used polyvinylphosphonic acid to prepare a flame retardant coating for cotton. Polyvinylphosphonic acid was used as crosslinking agent and benzophenone was added as catalyst. Crosslinking was induced by UV irradiation. Burning rate was reduced, especially when carbon nanotubes were incorporated in the coating.

High phosphorus content can be grafted into cellulose. As an example, Horrocks and Zhang have grafted up to $2.47 \mathrm{wt} \%$ of phosphorus onto cotton fabric using spirocyclicpentaerythritoldi(phosphonyl chloride) [37]. They used dimethylformamide (DMF) as solvent and the

\footnotetext{
* Corresponding author.

** Corresponding author. LCPM, Faculty of Sciences, Lebanese University, Fanar, Lebanon.

E-mail addresses: roland_hag@ul.edu.lb (R. El Hage), rodolphe.sonnier@mines-ales.fr (R. Sonnier).
} 
reaction was carried out during $4 \mathrm{~h}$ at $160{ }^{\circ} \mathrm{C}$. At lower temperature, the authors noted much lower grafted phosphorus content, only $0.5 \mathrm{wt} \%$ at $120{ }^{\circ} \mathrm{C}$. At $90{ }^{\circ} \mathrm{C}$, the reaction does not occur significantly. A temperature of $160{ }^{\circ} \mathrm{C}$ is too high and flax fibers would be degraded in such conditions.

In a previous work, Dorez et al. [28] modified flax fibers in relatively softer (or less severe) conditions through condensation reaction using octadecylphosphonic acid (ODPA) in ethanol/water (90/10 wt\%) solution. Flax fibers were immersed in the mixture and heated under reflux with stirring during $5 \mathrm{~h}$. Cellulose, xylan (as model compound for hemicellulose) and lignin were also treated separately through the same procedure and under the same conditions. The results allow assuming that the phosphonic function reacts only with aromatic hydroxyl groups of lignocellulosic fibers leading to the formation of phosphonate groups. Results showed that $5 \mathrm{wt} \%$ of ODPA were grafted onto flax fibers corresponding to only $0.5 \mathrm{wt} \%$ of phosphorus content.

In another previous work, Sonnier et al. [17] modified flax fabrics by reacting with dimethyl(methacryloxy)methyl phosphonate (MAPC1) and dimethylvinyl phosphonate (MVP) using an impregnation method coupled to electron beam irradiation. MVP was grafted into the bulk of elementary fibers while MAPC1 was located onto the surface only. Phosphorus content reached $4 \mathrm{wt} \%$ after dipping fabrics in a solution of $10 \mathrm{wt} \%$ MVP in tetrahydrofuran (THF), and irradiating them at $50 \mathrm{kGy}$. The authors also showed that high phosphorus contents can be achieved at lower doses ( $10 \mathrm{kGy})$ to reduce the degradation of flax fabrics. Flame retardancy was improved and self-extinguishing fabrics were prepared with only $1.5 \mathrm{wt} \%$ of phosphorus. However, THF must be considered with caution due to its toxicity and flammability. The use of solvents such as ethanol or water is more relevant.

In this paper, flax fabrics were treated using methods based on those discussed above. The first one involves the condensation reactions between phosphonic acid and aromatic hydroxyl groups. The second one is based on the phosphorylation of cellulose which can be significantly achieved at $160{ }^{\circ} \mathrm{C}$. Both these processes are called chemical modification in the following. The third one involves radiation grafting. To the best of our knowledge, no comparison between these methods has been carried out, especially with regard to flax fibers as substrate. Vinyl phosphonic acid was chosen for this study because it appears to be a good candidate because of its reactive phosphonic acid function and high phosphorus amount (27.8 wt\%). Contrarily to previous studies $[36,38]$, no additive was used to promote VPA reactivity. Moreover, vinyl phosphonic acid possesses a double bond $\mathrm{C}=\mathrm{C}$ and can be grafted using both methods allowing a relevant comparison. Fabrics were characterized to understand the effect of the grafting on their thermal stability and flame retardancy.

\section{Experimental}

\subsection{Materials}

Flax fabrics were kindly provided by Hexcel (France). Fabric weight is $200 \mathrm{~g} / \mathrm{m}^{2}$. The chemical composition of the flax fabric is $81 \mathrm{wt} \%$ of cellulose, $13 \mathrm{wt} \%$ of hemicelluloses and $2.7 \mathrm{wt} \%$ of lignin [17].

Vinyl phosphonic acid (VPA) (Fig. 1), (ABCR Germany), dimethylformamide (DMF) and absolute ethanol (Fisher Scientific) were

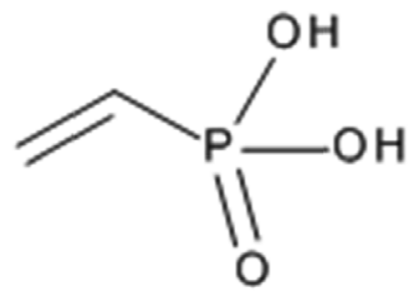

Fig. 1. Vinyl phosphonic acid (VPA). used as received without any purification.

\subsubsection{General procedure of flax fabrics modification by radiation grafting}

This modification involves three steps. In the first step, $2 \mathrm{~g}$ of flax fabrics $\left(9 \times 12 \mathrm{~cm}^{2}\right)$ were dipped 1 min into a VPA aqueous solution. The fabric/solution weight ratio was adjusted to be 1:10. The phosphonated monomer concentration in solution was adjusted to achieve a weight percentage of $1 \%, 5 \%$ and $10 \%$. Then fabrics were placed under an extractor hood at room temperature until total solvent evaporation had occurred (solvent evaporation was considered complete when weight was constant, usually after $24 \mathrm{~h}$ ). In the second step, fabrics were irradiated in air at room temperature using an electron beam accelerator (energy $9.8 \mathrm{MeV}$, power $27 \mathrm{~kW}$ ) by Ionisos SA (Chaumesnil, France). The chosen doses were 10, 20 and $50 \mathrm{kGy}$. In the third step, irradiated fabrics were washed 3 times for 1 min each by water at room temperature to remove the unbounded VPA monomers, oligomers or polymers.

\subsubsection{General procedure of flax fabrics treatment by chemical modification}

In a one-necked round-bottom flask $(50 \mathrm{~mL})$ equipped with a condenser, around $0.25 \mathrm{~g}$ of flax fabric $\left(5 \times 3 \mathrm{~cm}^{2}\right)$ was introduced into $20 \mathrm{~g}$ of the phosphonated solution. Different solutions were prepared in order to achieve different conditions according to the previous works of Dorez et al. and Horrocks and Zhang $[28,37]$. The first reaction solution was composed of ethanol/water $(90 / 10 \mathrm{w} / \mathrm{w})$ mixture containing $5 \mathrm{wt}$ $\%$ of VPA. The mixture was then heated under reflux $\left(70{ }^{\circ} \mathrm{C}\right)$. The second one was composed of $5 \mathrm{wt} \%$ of VPA dissolved in DMF. DMF was chosen because of its high boiling point. This mixture was heated at $100{ }^{\circ} \mathrm{C}$ and under reflux at $160{ }^{\circ} \mathrm{C}$ in order to achieve less and more severe conditions respectively. Based on previous results, the process duration was optimized at $2 \mathrm{~h}$. At the end of each treatment, the liquid phase was filtered. The treated flax fabrics were then washed three times with the corresponding treatment solvent and dried at room temperature to remove the ungrafted molecules.

Furthermore, three fabrics were modified in 1, 5 and $10 \mathrm{wt} \%$ of VPA aqueous solutions in the same conditions $(2 \mathrm{~h}$, heating under reflux at $100{ }^{\circ} \mathrm{C}$ ) in order to compare chemical modification and radiationgrafting methods with the same solvent. Flax fabrics were washed three times in demineralized water.

Whichever the considered treatment (radiation-grafting or chemical modification), preliminary tests have confirmed that three washing steps are enough to remove molecules able to be extracted from flax. After three washing steps, flax fiber weight does not change anymore. Moreover, in case of fabrics just impregnated, all molecules are removed after three washing steps.

The Table 1 summarizes the treatment conditions used in this work.

\subsubsection{Characterization}

2.1.3.1. X-ray fluorescence elemental analysis. An "Oxford XMET 5100" $\mathrm{X}$-ray fluorescence analyzer was used to determine the phosphorus elemental content in treated flax fabrics. Samples were fixed on a flat polymer holder which does not contain any phosphorus traces. This holder was used to flatten fabrics to reduce instrumental errors. Analyses were achieved under atmospheric pressure, without any preparation. The following settings were used as default: $13 \mathrm{kV}$ and $45 \mu \mathrm{A}$. Each spectrum was collected with a fixed measuring time (60 s). As the intensity of the phosphorus Ka peak is proportional to its concentration, the data were collected and converted by a simple calculation to determine the weight percentage of phosphorus. This instrument was calibrated before starting analysis using samples of known phosphorus concentration (measured by ICP-AES [17]). Thus, a calibration curve was drawn with a high correlation coefficient (supporting information). For each sample, peak intensity was converted into phosphorus weight percentage using this calibration curve. 


\begin{tabular}{|c|c|c|c|c|c|}
\hline & \multicolumn{4}{|l|}{ Chemical modification } & \multirow[t]{2}{*}{ Radiation-grafting } \\
\hline & $\begin{array}{l}\text { Most severe conditions (according to Horrocks } \\
\text { et al.) }\end{array}$ & Interm & conditions & $\begin{array}{l}\text { Softer conditions (according to Dorez } \\
\text { et al.) }\end{array}$ & \\
\hline Solvent & DMF & DMF & Water & Water/ethanol 90/10 & Water \\
\hline Temperature $\left({ }^{\circ} \mathrm{C}\right)$ & 160 & 100 & 100 & 70 & Room \\
\hline VPA content in solution (wt $\%$ ) & 5 & 5 & $1-10$ & 5 & $1-10$ \\
\hline Dose (kGy) & / & / & / & / & $10-50$ \\
\hline Washing & DMF & $\mathrm{DMF}$ & Water & Water/ethanol & Water \\
\hline
\end{tabular}

2.1.3.2. Scanning electron microscopy SEM. Fiber micrographs were obtained using an environmental scanning electron microscope, SEM, (FEI Quanta 200). Fibers were deposited on an adhesive wafer so that the cross-sections are located at the edge of the wafer. Samples were metallized in a high vacuum sputtering metallizer (Bal-Tec CED 030, Balzers) in order to avoid their charging during analysis. The prepared fibers were then analyzed using a vertical sample holder and micrographs were obtained under high vacuum at a voltage of $12.5 \mathrm{kV}$, with a working distance of $10 \mathrm{~mm}$. The SEM is equipped with an energy dispersive X-ray spectroscopy (Oxford INCA Energy system) which was used to determine the phosphorus location in the flax fibers.

2.1.3.3. Thermogravimetric analysis (TGA). A thermogravimetric apparatus (Setaram Setsys) was used to analyze the thermal degradation of the treated flax fabrics. Samples $(10 \mathrm{mg} \pm 1 \mathrm{mg}$ ) were heated under nitrogen atmosphere $(100 \mathrm{ml} / \mathrm{min})$ in alumina ceramic crucibles from 30 to $900{ }^{\circ} \mathrm{C}$ at a heating rate of $10{ }^{\circ} \mathrm{C} / \mathrm{min}$. Residual weight at $750{ }^{\circ} \mathrm{C}$, maximum degradation temperature (i.e. temperature of the mass loss rate peak) and maximum peak of mass loss rate (pMLR) were determined.

2.1.3.4. Pyrolysis combustion flow calorimetry (PCFC). A pyrolysis combustion flow calorimeter (Fire Testing Technology Ltd., UK) was used to investigate the fire behavior of samples at microscale $(2-4 \mathrm{mg})$. Samples were pyrolyzed at $1{ }^{\circ} \mathrm{C} / \mathrm{s}$ under a nitrogen flow of $100 \mathrm{~mL} / \mathrm{min}$ from 90 to $750{ }^{\circ} \mathrm{C}$ (anaerobic pyrolysis - method A according to the standard ASTM D7309). Pyrolysis gases were carried to a combustor in the presence of a $\mathrm{N}_{2} / \mathrm{O}_{2}(80 / 20)$ mixture. In such conditions, all gases are fully oxidized. Heat Rate Release (HRR) is calculated according to Huggett's relation [39] which states that $1 \mathrm{~kg}$ of consumed oxygen corresponds to 13.1 MJ of heat release. Each sample was tested twice to ensure the reproducibility of our measurements.

The peak of heat rate release (pHRR), the temperature at pHRR (Tmax), and the total heat release (THR), were determined.

2.1.3.5. Preliminary fire test on fabrics. An unstandardized fire test was carried out to assess the flammability of some fabrics [17]. The bottom of fabrics samples (around $0.5 \mathrm{~g}$-dimensions: $4 \times 2 \mathrm{~cm}^{2}$ ) are pinched between two glass plates and maintained vertically. A cigarette lighter is used to ignite the top of fabrics. This method allows the fabrics selfextinguishment to be evaluated, i.e. absence of flame spreading. The residue is also weighted after complete burning. The weight of the part of fabric pinched between plates is subtracted to the initial weight and to the residue weight to calculate correctly the mass loss percentage. For self-extinguishing fabric, complete burning is reached by multiple flame applications. As already shown in our previous work, this test is reproducible and allows assessing the self-extinguishment and the charring of the fabrics. This information is sufficient to guide our research and development efforts. The Fig. 7 and the supplementary video of our previous work [17] illustrate the test.

\section{Results and discussion}

\subsection{Chemical modification}

Flax fabrics were treated under less severe conditions $\left(100{ }^{\circ} \mathrm{C}\right.$ or heating under reflux) during $2 \mathrm{~h}$ with VPA dissolved in demineralized water, ethanol/water (90/10) and DMF with different concentrations as explained previously. Furthermore, flax fabrics were treated in severe conditions for $2 \mathrm{~h}$ with $5 \mathrm{wt} \% \mathrm{VPA}$ in DMF at $160^{\circ} \mathrm{C}$. This latter process probably extracts some components from the flax fabrics and changes its composition. Indeed, a modification in solution color from transparent to brown was observed whether if the VPA molecule is dissolved in DMF or not. According to literature [39], DMF used in non-wood fibers pulping leads to a selective hydrolysis delignification reaction (lignin extraction) with a lower effect on carbohydrate degradation.

Fig. 2 shows the remaining phosphorus content measured by X-ray fluorescence for the treated flax fabrics after the different processes.

Grafted phosphorus yields after grafting under less severe conditions are very low $(<0.25 \mathrm{wt} \%)$. According to the work of Dorez et al., phosphonic acid condensation in such conditions involves only phenol groups which are present in the lignin fraction [28]. As lignin content in flax is very low (typically about $2.7 \mathrm{wt} \%$ ), the possibility to graft phosphonic functions may thus be limited. Under more severe conditions, phosphorus content was much higher and reached $2.3 \mathrm{wt} \%$. According to Horrocks et al. [37], maximum phosphorylation of cellulose occurs at $160{ }^{\circ} \mathrm{C}$ after $2 \mathrm{~h}$ refluxing. In their study, the grafted phosphorus yield was $2.39 \mathrm{wt} \%$ using spirocyclic pentaerythritol diphosphochloridate (SPDPC) dissolved in DMF with a mass ratio (SPDPC/ sample) of $4: 1$ of at $160{ }^{\circ} \mathrm{C}$ after $2 \mathrm{~h}$ refluxing. This corresponds to $11.5 \mathrm{wt} \%$ of SPDPC. This content is in good agreement with the value obtained in the present study ( $2.3 \mathrm{wt} \%$, i.e. $8.3 \mathrm{wt} \%$ of VPA) since mass ratio (VPA/flax fabric), solvent, refluxing temperature and time were selected according to the work of Horrocks et al. The slightly lower content obtained in the present study may be due to a lower cellulose content of the substrate ( $81 \mathrm{wt} \%$ versus $94 \mathrm{wt} \%$ ). Moreover Horrocks et al. carried out a pretreatment of cotton using $\mathrm{NaOH}$ to increase the accessibility of cellulose.

\subsection{Radiation grafting}

Flax fabrics were dipped in VPA aqueous solutions with different concentrations and irradiated at different radiation doses (after solvent removal). Phosphorus content was also measured by X-ray fluorescence (Fig. 2). For $1 \mathrm{wt} \%$ of VPA in solution irradiated at $50 \mathrm{kGy}$, the resulting fabric contained $0.26 \mathrm{wt} \%$ of phosphorus. Higher concentrations of VPA led to higher grafted phosphorus contents and $1.10 \mathrm{wt} \%$ and $1.38 \mathrm{wt} \%$ of phosphorus were grafted respectively for $5 \mathrm{wt} \%$ and $10 \mathrm{wt}$ $\%$ VPA solutions at this same radiation dose. Such high contents are in good agreement with results obtained by Sonnier et al. [17] when the phosphorus flame retardant (MVP) was able to penetrate into the individual fiber's bulk. Moreover, it was shown that the concentration of FR in the solution was the main parameter allowing the final phosphorus content to be controlled. By using a solution containing $10 \mathrm{wt} \%$ 


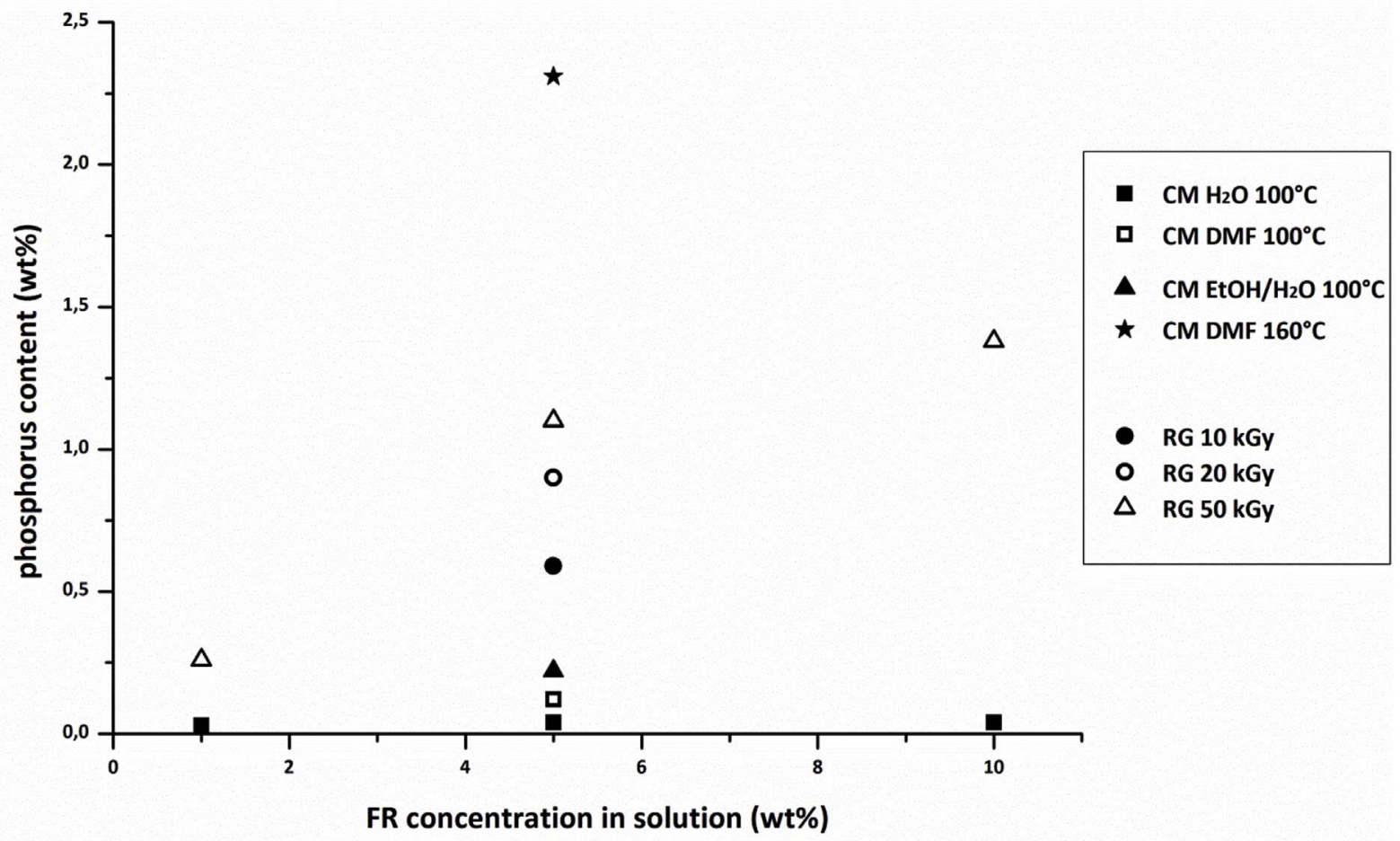

Fig. 2. Phosphorus content of flax fabrics modified by the different processes. $(\mathrm{CM}=$ chemical modification, $\mathrm{RG}=$ radiation grafting $)$.

Table 2

Change in weight (in comparison to initial weight) and grafting efficiency for all fibers treated through radiation grafting.

\begin{tabular}{|c|c|c|c|c|c|}
\hline \multirow{2}{*}{$\begin{array}{l}\text { VPA } \\
\text { concentration } \\
\text { in } \\
\text { impregnation } \\
\text { solution (wt } \% \text { ) }\end{array}$} & \multirow{2}{*}{$\begin{array}{l}\text { Radiation } \\
\text { dose (kGy) }\end{array}$} & \multicolumn{2}{|c|}{ Change in weight (\%) } & \multirow{2}{*}{$\begin{array}{l}\text { Grafting } \\
\text { efficiency } \\
(\%)\end{array}$} & \multirow{2}{*}{$\begin{array}{l}\text { Phosphorus } \\
\text { content (wt } \\
\% \text { ) }\end{array}$} \\
\hline & & $\begin{array}{l}\text { After } \\
\text { irradiation }\end{array}$ & $\begin{array}{l}\text { After } \\
\text { washing }\end{array}$ & & \\
\hline 1 & 50 & +2.0 & -0.2 & $\sim 0^{\mathrm{a}}$ & 0.26 \\
\hline 5 & 10 & +10.2 & +1.7 & 17.1 & 0.59 \\
\hline 5 & 20 & +9.4 & +2.3 & 23.9 & 0.90 \\
\hline 5 & 50 & +10.1 & +2.7 & 26.5 & 1.10 \\
\hline 10 & 50 & +21.8 & +6.7 & 31.0 & 1.38 \\
\hline
\end{tabular}

${ }^{a}$ Grafting efficiency is based on gravimetric changes of the fibers which could be influenced by other factors like humidity and room temperature giving negative values. This error is more significant at low concentrations than higher ones.

of MVP, a high phosphorus content was achieved (around $4 \mathrm{wt} \%$ at $50 \mathrm{kGy}$ ). However, the radiation dose is also an important parameter in controlling the final phosphorus content since grafting efficiency is influenced by radiation dose (Table 2).

Grafting efficiency is calculated as the ratio between the amount of VPA remaining after washing and the amount of VPA before washing and immediately following irradiation.

It is noteworthy that the weight after irradiation is similar to the weight after dipping and solvent removal, evidencing that no significant volatilization occurs between impregnation and irradiation. As shown in Table 2, grafting efficiency increases with radiation dose. The phosphorus content increases from $0.59 \mathrm{wt} \%$ at $10 \mathrm{kGy}$ to 0.90 and $1.10 \mathrm{wt} \%$ at 20 and $50 \mathrm{kGy}$ despite a similar weight uptake after dipping and solvent removal. A low irradiation dose is not sufficient to break all the $\mathrm{C}=\mathrm{C}$ double bonds and thus a larger fraction of VPA will not react and will be removed during the washing step. Thus a minimum radiation dose is needed to graft sufficient amount of phosphorus while avoiding the degradation of flax fibers [39]. Note that another mechanism can be responsible for the high VPA content remaining in flax fibers after washing. Indeed, VPA is able to homopolymerize under radiation. Therefore, oligomers or homopolymers may be trapped into the fiber structure and unable to removed by washing.

\subsubsection{Comparison between condensation reaction and radiation grafting}

In order to compare the quantity of phosphorus grafted on the flax fabrics by each reaction pathway, fabrics were treated in the same concentrations with the same solvent (water). Phosphorus contents achieved by phosphonic acid condensation reactions in these operating conditions were much lower than by radiation-grafting. The maximal amount of phosphorus obtained using the chemical method was $0.04 \mathrm{wt}$ $\%$ with a $5 \mathrm{wt} \%$ VPA solution whereas the minimal quantity of phosphorus obtained through the radiation grafting was 0.26 and $1.10 \mathrm{wt} \%$ with a 1 and $5 \mathrm{wt} \%$ VPA solutions respectively.

Phosphorus mapping (Fig. 3) of flax fabrics treated by $5 \mathrm{wt} \%$ VPA dissolved in demineralized water shows that phosphorus has penetrated into the bulk of the fibers for both modification methods. In both cases, phosphorus is homogeneously located from the surface to the bulk of the fiber. Same observations were carried out for all treated fabrics whichever the process conditions. In the previous work of Sonnier et al. [17], high phosphorus content in the flax fiber was assigned to the diffusion of the grafted molecule into the fiber bulk. Indeed, authors showed that dimethyl(methacryloxy)methyl phosphonate (MAPC1) was only located on the surface and in this case phosphorus content was very low, whereas dimethylvinyl phosphonate (MVP) was present from the surface to the bulk of the modified fibers leading to a high phosphorus content. The results obtained in the present work cannot be explained by a difference in terms of flame retardant diffusion. It seems more related to the flax composition and to the low reactivity of VPA under selected conditions for chemical modification as explained previously. 

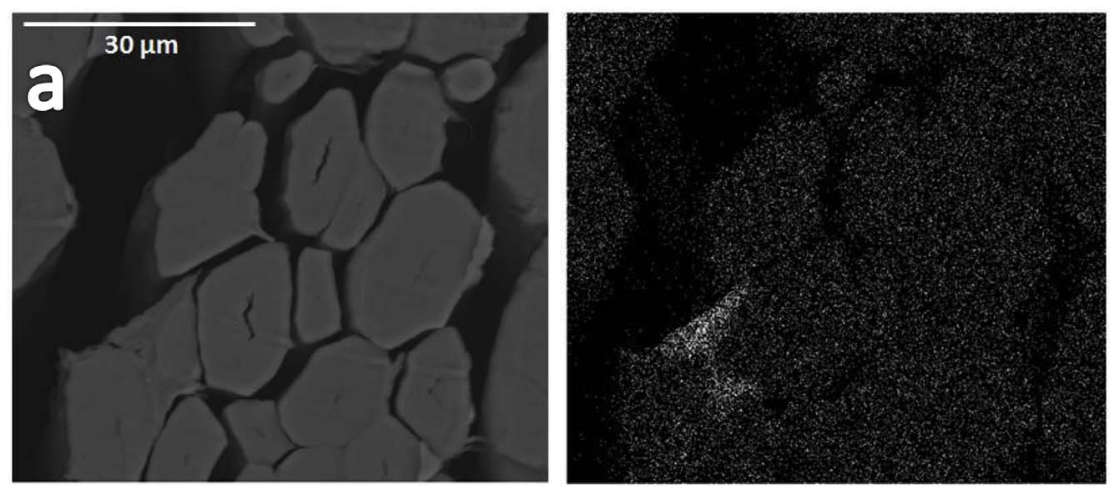

Fig. 3. SEM images (left) and EDX phosphorus mapping (right) of flax fabrics treated by $10 \mathrm{wt} \%$ VPA aqueous solutions by (a) Chemical Modification (b) and radiation grafting at $50 \mathrm{kGy}$.
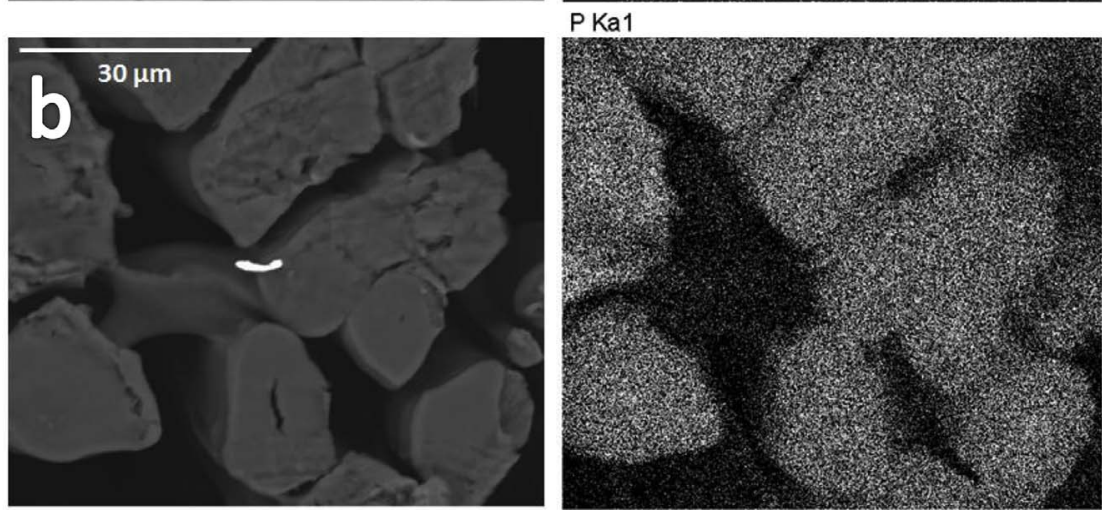

P Ka1

As a conclusion, it can be assumed that irradiation allows high phosphorus amount to be grafted, even at low dose (10-20 kGy). Such radiation dose is low enough to avoid a degradation of flax fibers. Chemical modification can also lead to high phosphorus amount but only in severe conditions, which are very degrading. Soft conditions lead to very low phosphorus yield, which is insufficient to ensure good fire performances, as shown in the following. Fig. 4 summarizes the reactions involved in the phosphorylation of flax using the different methods.

\subsubsection{Thermal degradation at microscale}

The effect of the phosphorus content on the flax fabrics was studied through thermogravimetric analysis and pyrolysis combustion flow calorimetry (anaerobic pyrolysis). Fig. 5 shows the HRR and MLR curves for the untreated flax fabric and for the fabric modified with $1.38 \mathrm{wt} \%$ of phosphorus using radiation grafting (10 wt $\%$ of VPA in water, $50 \mathrm{kGy}$ ). Table 3 summarizes the main data for all fabrics.

The anaerobic decomposition of flax involves different steps corresponding to the main flax components, i.e. hemicelluloses, cellulose and lignin. These decomposition steps are usually overlapped resulting in the formation of one large peak [40]. This main peak is observed in both characterization methods (208 W/g in PCFC and 19.3\%/min in TGA for unmodified flax). The peak temperature is slightly shifted towards higher value in PCFC analysis $\left(364{ }^{\circ} \mathrm{C}\right.$ versus $346{ }^{\circ} \mathrm{C}$ in TGA for unmodified flax) because the heating rate is higher. A small mass loss step around $100{ }^{\circ} \mathrm{C}$ in TGA around $100{ }^{\circ} \mathrm{C}$ and corresponds to the release of water contained in flax fabrics. This step cannot be observed in PCFC because water vapor is a non-flammable compound that does not react with oxygen in the combustor.

The intensity of the peak, its temperature and the residue content gradually change according to the phosphorus content. These tendencies are very common for phosphorus-containing flame retardants used to promote charring of a large range of substrates. As the temperature increases, phosphorus flame retardant decomposes leading to the formation of phosphoric acid. The phosphoric acid formed can phosphorylate cellulose leading to the formation of phosphorus ester. These esters accelerate the dehydration of cellulose promoting the formation of char [11]. Thus the thermal stability decreases while the char yield increases.

While the phosphorus content reached after chemical modification in relatively soft or intermediate conditions (in water or DMF) remains very low $(0.22 \mathrm{wt} \%$ or less), the decomposition of flax is only slightly affected. Peak temperature decreases from 364 to $310-340{ }^{\circ} \mathrm{C}$. The char yield increases from $14.7 \mathrm{wt} \%$ to $16.5-24.5 \mathrm{wt} \%$. Unexpectedly, the peak of hat release rate and the peak of mass loss rate slightly increase as well as the Total Heat Release. This result suggests a flax degradation or depolymerisation during the process (Table 3). As an example, the modification with $10 \mathrm{wt} \%$ of VPA in water (i.e. only $0.04 \mathrm{wt} \%$ of grafted phosphorus) leads to an increase of pHRR and pMLR from $208 \mathrm{~W} / \mathrm{g}$ to $276 \mathrm{~W} / \mathrm{g}$ and from $19.3 \% / \mathrm{min}$ to $23.8 \%$ /min respectively. THR also increases and reaches $12.6 \mathrm{~kJ} / \mathrm{g}$ even if the residue content at $750{ }^{\circ} \mathrm{C}$ is slightly enhanced. In order to understand these results, flax fabrics were also treated with different solvents at different temperatures but without VPA to observe if the process itself has an impact on the fire properties of the fabrics. As the Table 3 shows, the process without VPA in water or DMF has only a limited influence on pHRR but a negligible one on THR. As the vinyl phosphonic acid concentration increases, the solution may become more acidic and thus more degradant for flax. This point needs further investigations.

On the contrary, the fabric treated with VPA in DMF using severe conditions exhibits a high phosphorus content and so a lower thermal stability $\left(\mathrm{T}_{\max }=282{ }^{\circ} \mathrm{C}\right)$. The peak of mass loss rate decreases to $8.9 \%$ / min while the peak of heat rate release decreases to $75 \mathrm{~W} / \mathrm{g}$. With such high phosphorus content (2.31 wt\%), residue content highly increases up to $41.1 \mathrm{wt} \%$ and total heat release is as low as $2.3 \mathrm{~kJ} / \mathrm{g}$.

Similarly, radiation grafting leads to significant changes in TG and HRR curves due to high phosphorus content grafted on flax fabrics. The pHRR temperature decreases to $281-266{ }^{\circ} \mathrm{C}$ when phosphorus content exceeds $0.5 \mathrm{wt} \%$. The peak of mass loss rate (pMLR) decreases from $19.3 \% / \mathrm{min}$ for untreated flax to $7.5 \% / \mathrm{min}$ for flax treated with $10 \%$ VPA by radiation grafting. This result is in a good agreement with PCFC results where pHRR decreases from 208 to $47 \mathrm{~W} / \mathrm{g}$. Total heat release 


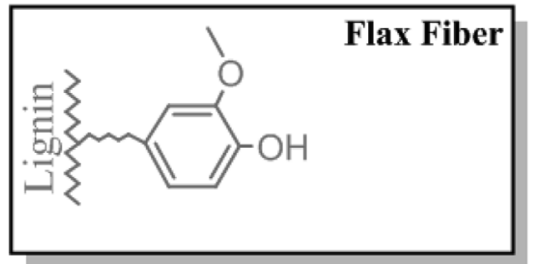

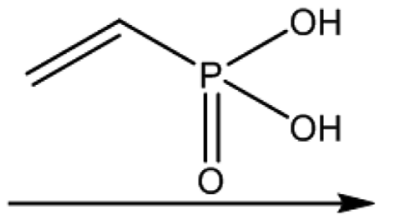

Condensation reaction
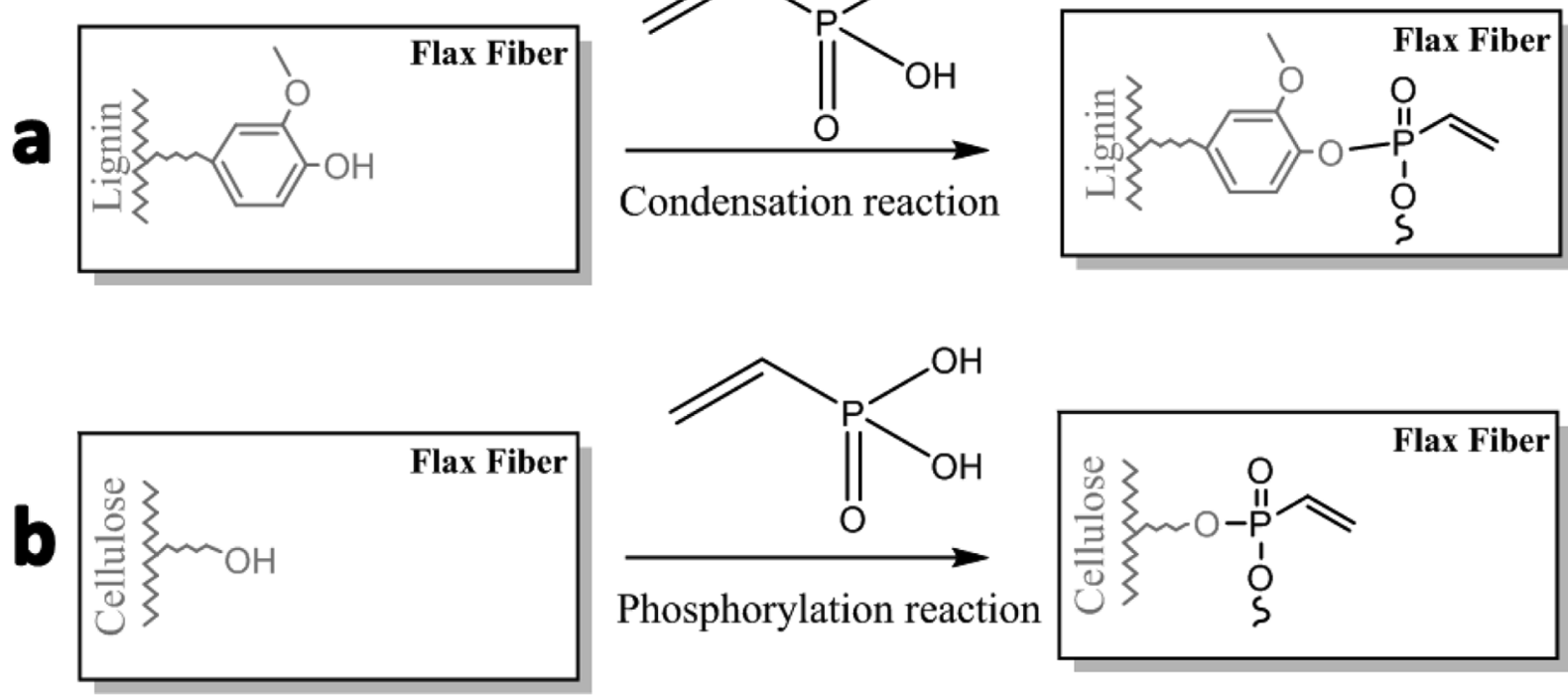

Phosphorylation reaction
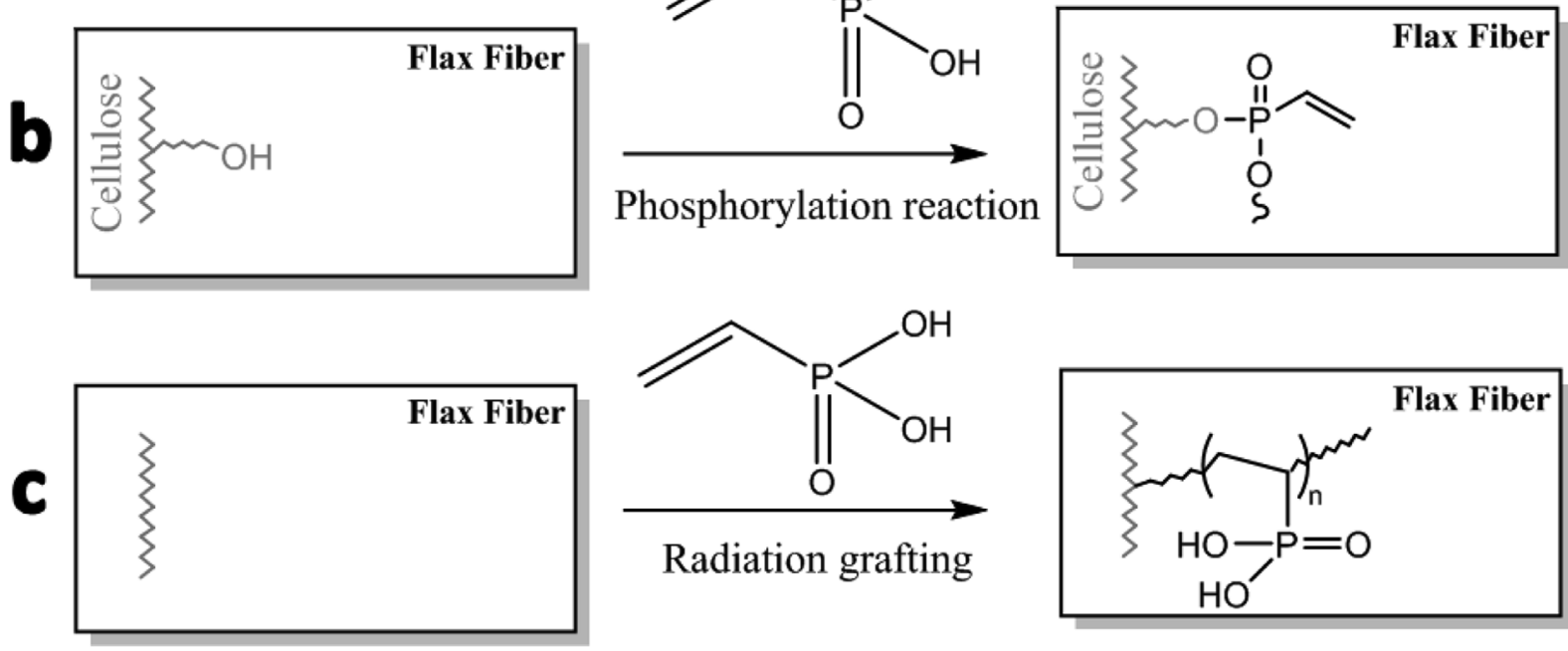

Fig. 4. VPA grafting reactions on flax fibers through (a) chemical modification in soft conditions, (b) chemical modification in severe conditions, (c) radiation grafting.

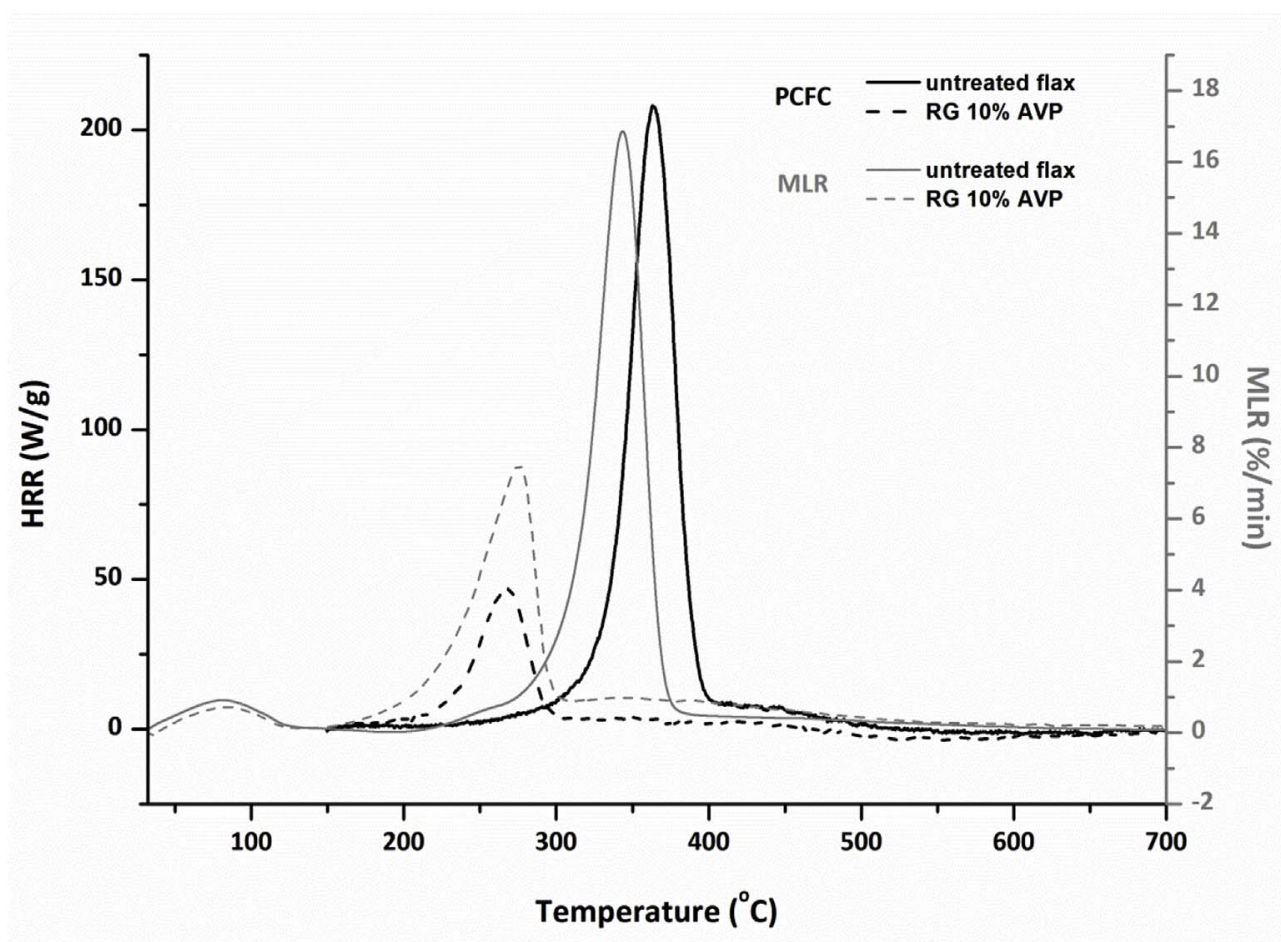

Fig. 5. HRR and MLR curves for the untreated flax fabric and for the fabric modified with $10 \mathrm{wt}$ $\%$ of VPA using radiation grafting at $50 \mathrm{kGy}$.

also decreases as phosphorus content increases in these fabrics. It reaches $2.0 \mathrm{~kJ} / \mathrm{g}$ after the radiation grafting with $10 \% \mathrm{VPA}$. This decrease is correlated with the high char content (between 27 and $37 \mathrm{wt}$ $\%)$.
On the whole the flammability of flax at microscale is mainly influenced by the phosphorus content as shown in Fig. 6. The results show the same tendency already noted by Sonnier et al. [17] when another flame retardant (MVP) was radiation grafted onto flax fabrics. 
Table 3

Main data measured by PCFC and TGA for different compositions.

\begin{tabular}{|c|c|c|c|c|c|c|c|c|c|}
\hline & \multirow[t]{2}{*}{ [VPA] } & \multirow[t]{2}{*}{ Solvent } & \multirow[t]{2}{*}{ Condition } & \multirow[t]{2}{*}{$\% \mathrm{P}$} & \multicolumn{3}{|l|}{ PCFC } & \multicolumn{2}{|l|}{ TGA } \\
\hline & & & & & Peak temperature $\left({ }^{\circ} \mathrm{C}\right)$ & pHRR (W/g) & THR (KJ/g) & pMLR (\%/min) & Res750 ${ }^{\circ} \mathrm{C}(w \mathrm{t} \%)$ \\
\hline & Untreat & flax & & 0 & 364 & 208 & 9.3 & 19.3 & 14.7 \\
\hline \multirow[t]{9}{*}{ Chemical Modification } & $0 \%$ & $\mathrm{H}_{2} \mathrm{O}$ & $100{ }^{\circ} \mathrm{C}$ & 0 & 366 & 240 & 9.4 & - & - \\
\hline & $1 \%$ & $\mathrm{H}_{2} \mathrm{O}$ & $100{ }^{\circ} \mathrm{C}$ & 0.03 & 338 & 241 & 9.8 & 25.3 & 16.9 \\
\hline & $5 \%$ & $\mathrm{H}_{2} \mathrm{O}$ & $100{ }^{\circ} \mathrm{C}$ & 0.04 & 331 & 222 & 11.4 & 27.0 & 16.5 \\
\hline & $10 \%$ & $\mathrm{H}_{2} \mathrm{O}$ & $100{ }^{\circ} \mathrm{C}$ & 0.04 & 335 & 276 & 12.6 & 23.8 & 22.4 \\
\hline & $5 \%$ & $\mathrm{EtOH} / \mathrm{H}_{2} \mathrm{O}$ & $70{ }^{\circ} \mathrm{C}$ & 0.22 & 310 & 194 & 8.7 & 19.3 & 23.5 \\
\hline & $0 \%$ & DMF & $100{ }^{\circ} \mathrm{C}$ & 0 & 365 & 229 & 8.6 & - & - \\
\hline & $5 \%$ & DMF & $100{ }^{\circ} \mathrm{C}$ & 0.12 & 338 & 263 & 10.1 & 22.0 & 24.5 \\
\hline & $0 \%$ & DMF & $160^{\circ} \mathrm{C}$ & 0 & 364 & 196 & 9.5 & - & - \\
\hline & $5 \%$ & DMF & $160{ }^{\circ} \mathrm{C}$ & 2.31 & 282 & 75 & 2.3 & 8.9 & 41.1 \\
\hline \multirow[t]{5}{*}{ Radiation Grafting } & $1 \%$ & $\mathrm{H}_{2} \mathrm{O}$ & 50 kGy & 0.26 & 308 & 190 & 7.0 & 17.7 & 27.2 \\
\hline & $5 \%$ & $\mathrm{H}_{2} \mathrm{O}$ & 10 kGy & 0.59 & 281 & 88 & 4.8 & 11.1 & 31.8 \\
\hline & $5 \%$ & $\mathrm{H}_{2} \mathrm{O}$ & 20 kGy & 0.90 & 278 & 83 & 3.5 & 10.7 & 29.9 \\
\hline & $5 \%$ & $\mathrm{H}_{2} \mathrm{O}$ & 50 kGy & 1.10 & 272 & 60 & 3.2 & 10.8 & 32.3 \\
\hline & $10 \%$ & $\mathrm{H}_{2} \mathrm{O}$ & 50 kGy & 1.38 & 266 & 47 & 2.0 & 7.5 & 37.8 \\
\hline
\end{tabular}

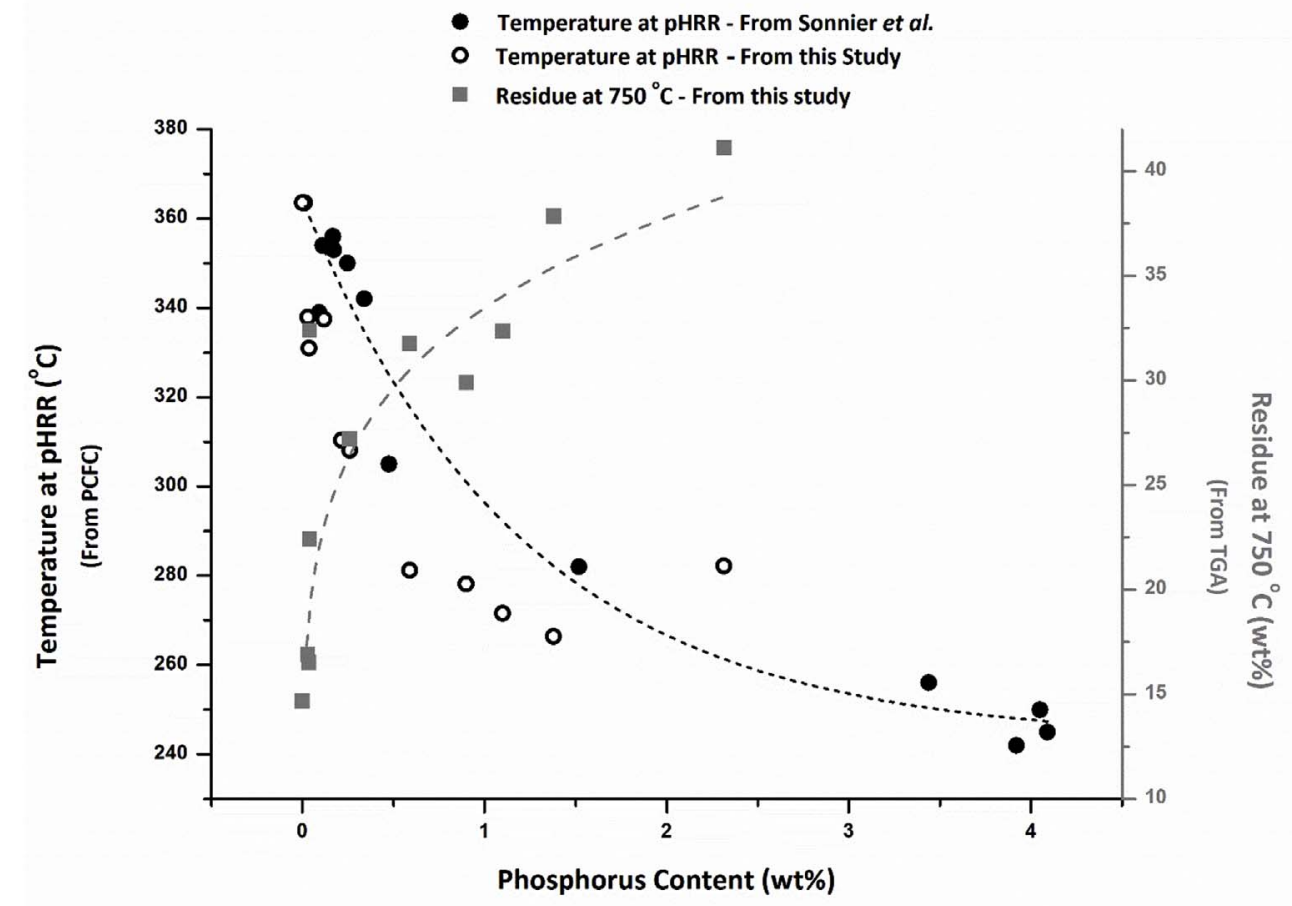

Fig. 6. Influence of phosphorus content on temperature at PHRR of flax fibers using PCFC and residue content using TGA (dotted lines are only guidelines for eyes).

\subsubsection{Phosphorus effect on flax fabrics flammability}

Fire tests were performed on flax fabrics modified by VPA in order to assess the effect of this modification on flame retardancy. Unmodified flax fabric leaves low residue after ignition which degrades totally few seconds later due to thermo-oxidation (aerobic pyrolysis when the flame moves away - Fig. 7a). Final char yield in this case is close to $0 \%$. Modified fabrics exhibit two different behaviors. For some of them, flame propagation is observed even if a stable residue is formed which does not degrade by thermo-oxidation (Fig. 7b). Other fabrics are self-extinguishing. Multiple ignitions using lighter are needed to burn the whole sample (Fig. 7c).

Fig. 8 shows the relation between the fire test results and the phosphorus content. It is well known that flame retardancy level depends in many cases on the phosphorus content in the sample [41]. To reach self-extinguishing behavior, phosphorus concentrations in flax fabrics should be ranged between 0.5 and $1.5 \mathrm{wt} \%$ [17]. Moreover, selfextinguishment is observed to be correlated to char yield.

VPA does not allow obtaining self-extinguishing fabrics when grafting was carried out using the chemical treatment in soft conditions. Phosphorus content is systematically below $0.5 \mathrm{wt} \%$. For fabrics treated with 5\% VPA in ethanol/water, phosphorus content is the highest ( $0.22 \mathrm{wt} \%)$, but self-extinguishment is not observed. Char yield in this case is around $6 \mathrm{wt} \%$ which is the highest char value for fabrics treated in soft conditions. This is obviously due to the low phosphorus content grafted on the flax fabrics.

However, self-extinguishing behavior is observed with fabrics treated with VPA by radiation grafting or chemical modification in DMF at $160{ }^{\circ} \mathrm{C}$. With $0.59 \mathrm{wt} \%$ of phosphorus, flax fabric is self-extinguishing. Flame out occurs few seconds after igniting sample. Char residue is $17.2 \mathrm{wt} \%$. With higher phosphorus content of 0.90 and 

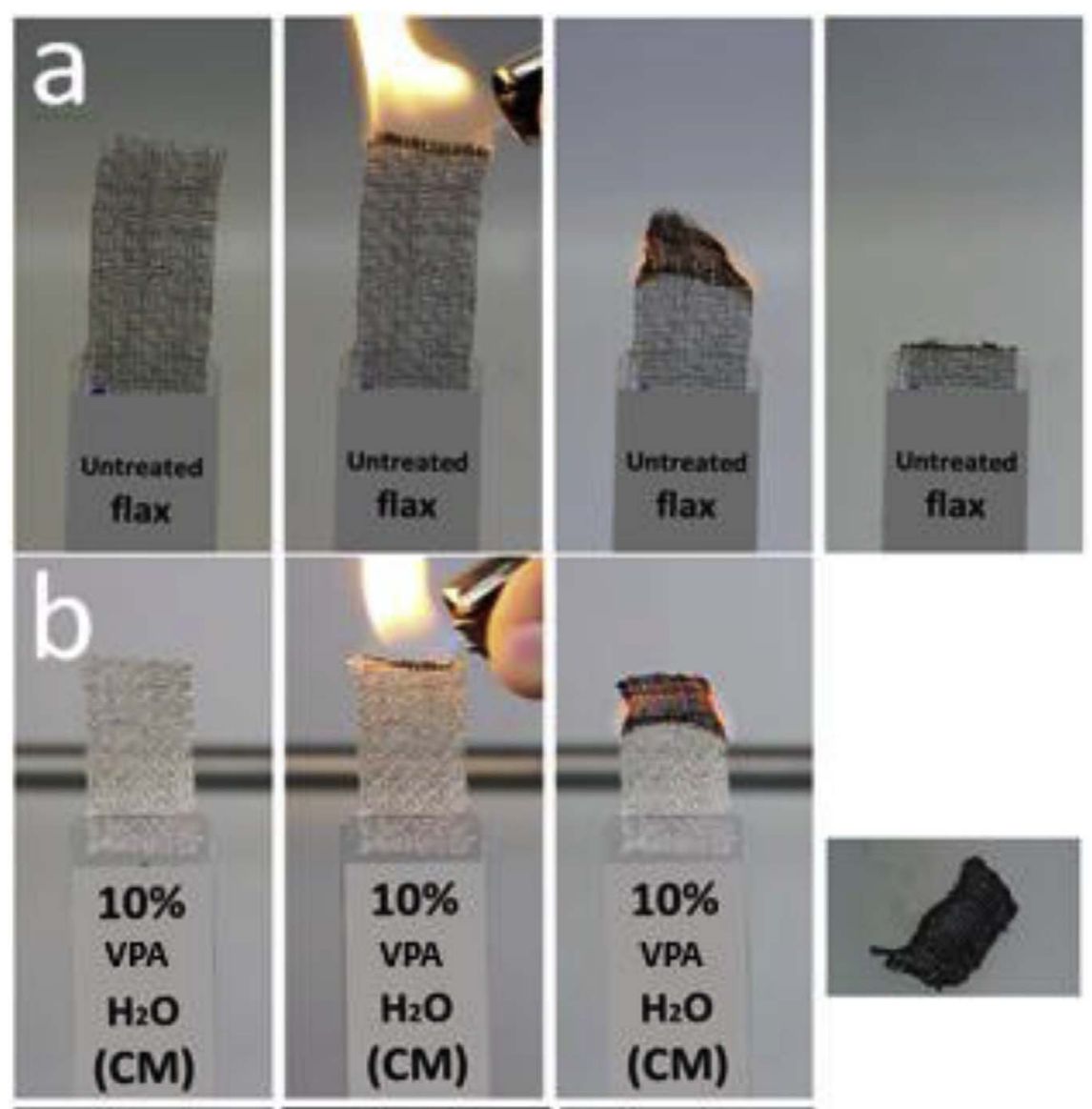

Fig. 7. Preliminary fire test on a) untreated, b) chemically modified (CM), and c) irradiated (RG) flax fabrics.
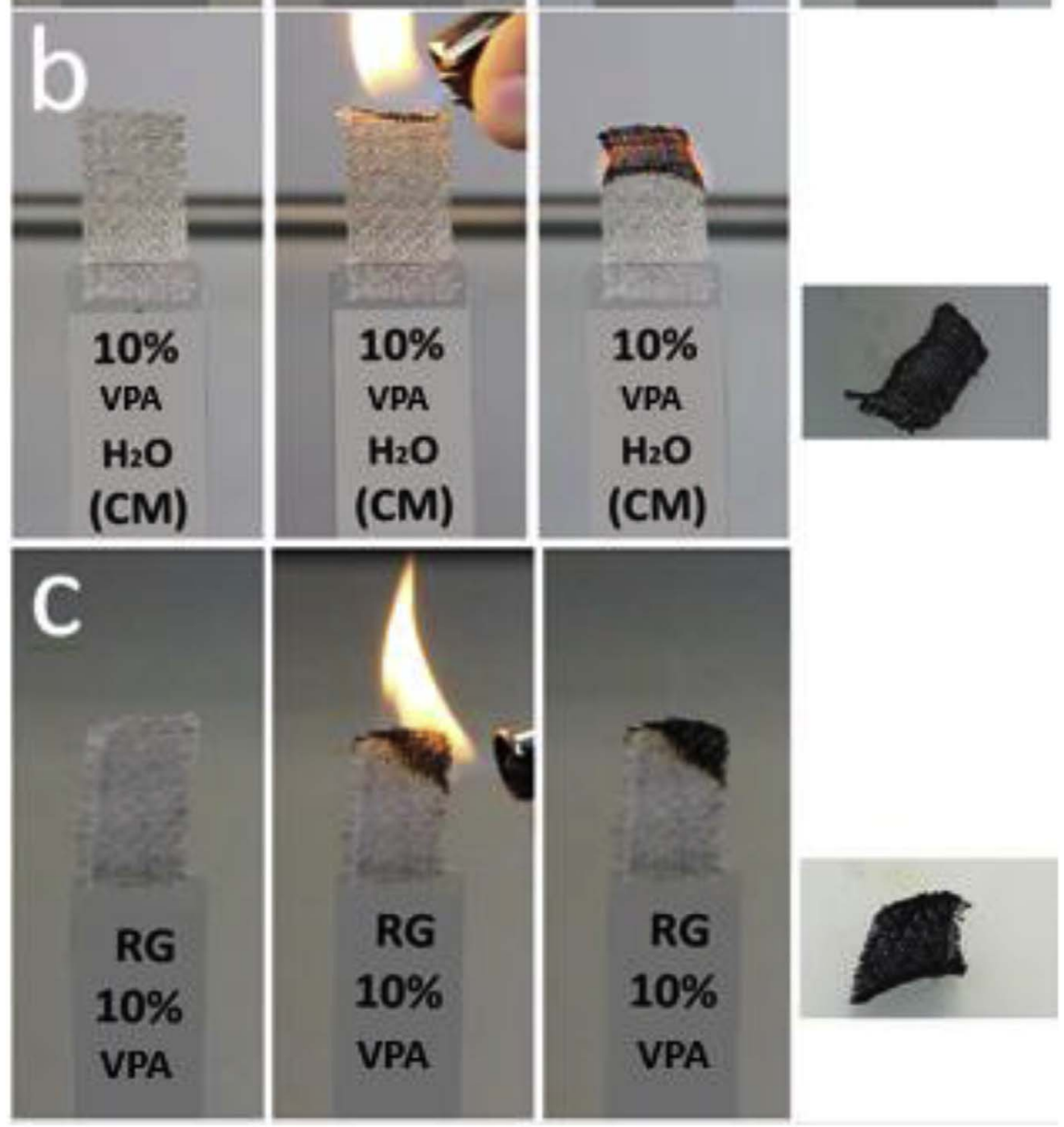

$1.10 \mathrm{wt} \%$, flax fabrics are also self-extinguishing leaving 20 and $21.9 \mathrm{wt}$ $\%$ of char residue. For 1.38 and 2.31 wt $\%$ of phosphorus flax fabrics shows non-flammable behavior. No flame formation and propagation is observed after fire source application. Despite that, fabrics color changes into dark due to a partial decomposition and char formation. Residues of 28.4 and $32.9 \mathrm{wt} \%$ are respectively obtained by maintaining the fire source on the treated fabrics throughout the fire test. Chars are formed due to the fabric pyrolysis under lighter's flame temperature.

It has been proved previously that char content increases approximately linearly with phosphorus content from MVP [17]. In this study, the same behavior is observed with VPA whichever the grafting method. Moreover, the phosphorus content threshold to obtain selfextinguishment seems to be confirmed between 0.5 and $1.5 \mathrm{wt} \%$ by the present results (Fig. 8).
Obviously TGA and fire test are different and cannot be easily compared. In fire test, pyrolysis is usually considered anaerobic as in TGA. But the formed char is able to degrade when the flame moves away due to thermo-oxidation. This phenomenon is well observed for non-self-extinguishing fabrics. Note that the residue in TGA (anaerobic pyrolysis) is higher than the char yield from fire test (Fig. 9). This discrepancy is especially important $(+15-20 \mathrm{wt} \%)$ when the phosphorus content is low $(<0.5 \mathrm{wt} \%)$. When the phosphorus content is higher, the char yield from fire test becomes closer to the TGA residue (only $+5 \mathrm{wt} \%$ for $2.31 \mathrm{wt} \%$ of phosphorus), i.e. it does not degrade anymore when the flame vanishes or moves away. This evidences that phosphorus increases not only the char yield but also its resistance to thermo-oxidation, as already shown in a previous work [42]. 


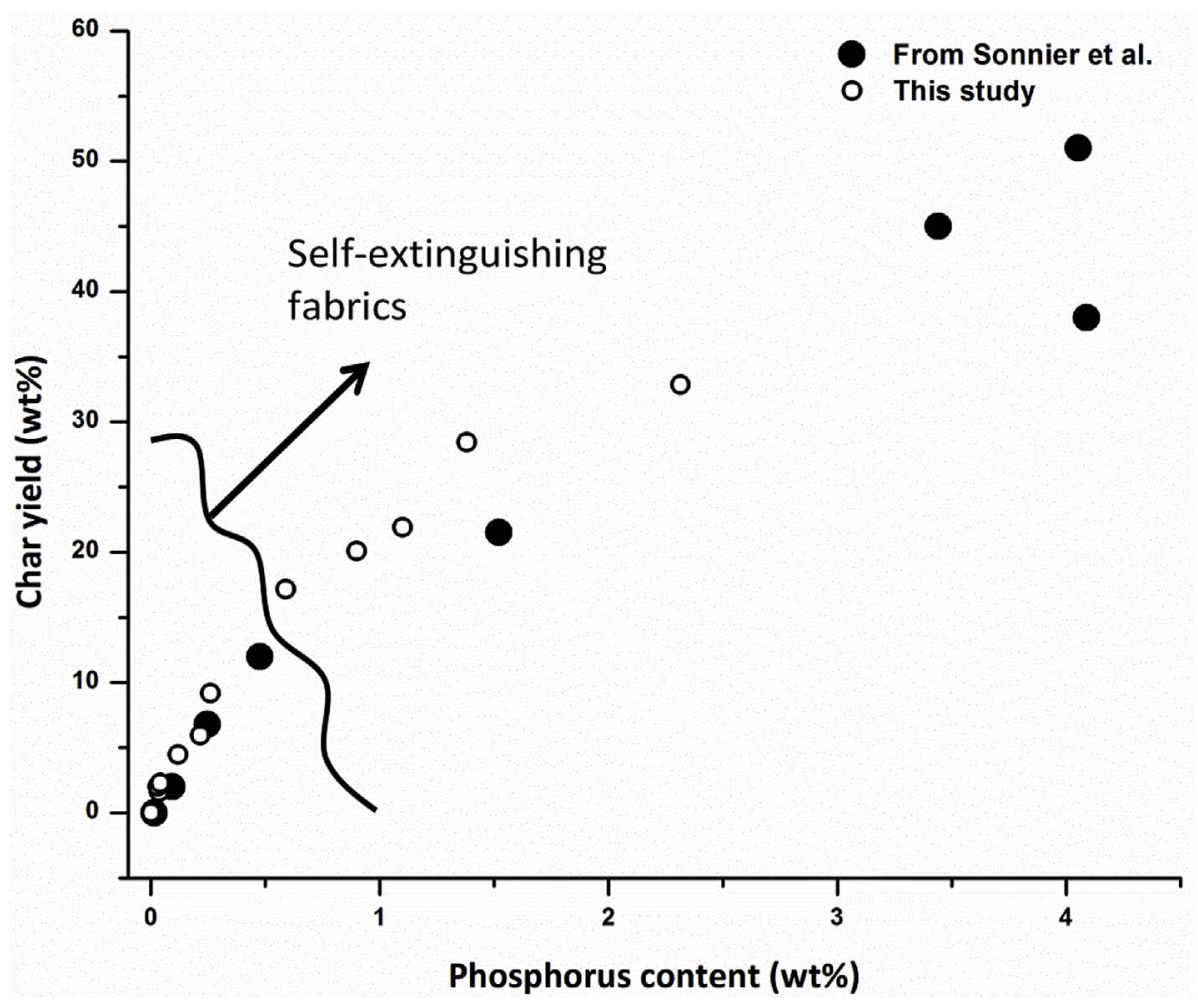

Fig. 8. Char yield versus phosphorus content obtained from fire test.

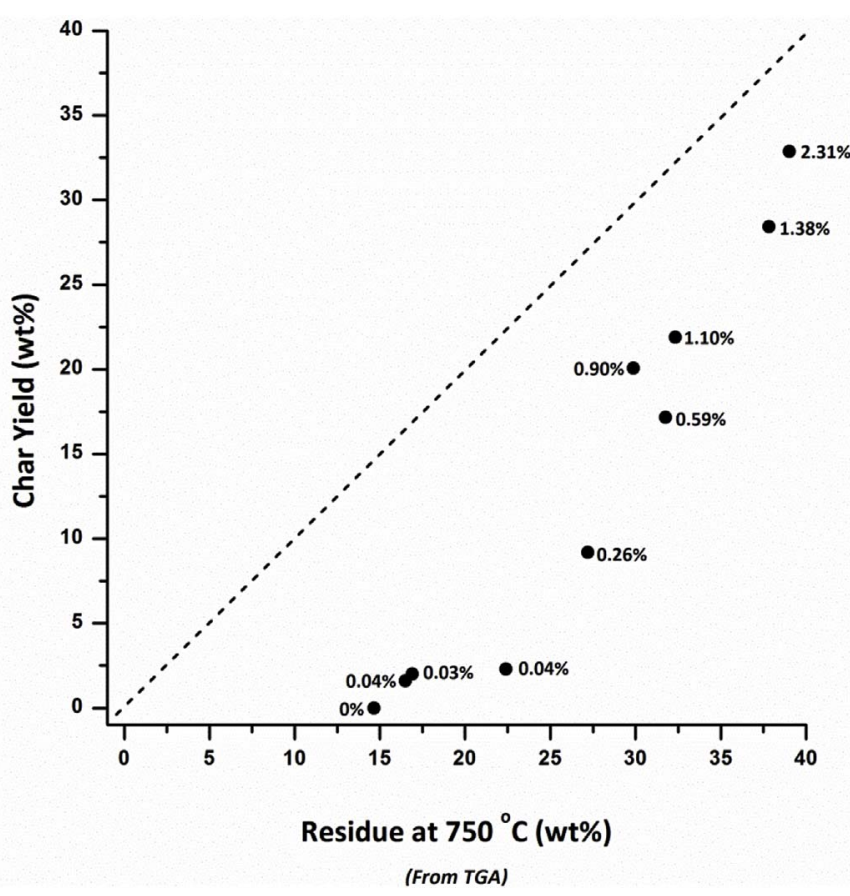

Fig. 9. Char yield obtained from fire test in function of residue content at $750{ }^{\circ} \mathrm{C}$ obtained from thermogravimetric analysis (labels correspond to phosphorus content of flax fabrics).

\section{Conclusion}

In order to prepare flame retarded flax fabrics, three methods were compared. The first one is based on the condensation reaction of phosphonic acid with phenol groups of flax (mainly lignin). The second one is based on the phosphorylation of cellulose. The third one is based on radiation grafting based on the reactivity of carbon-carbon double bond in presence of free radicals. Self-extinguishing fabrics have been noticed only when grafted phosphorus content is high enough ( $>0.5-1 \mathrm{wt} \%$ ). Only radiation grafting and chemical modification in severe conditions (i.e. in DMF at $160^{\circ} \mathrm{C}$ ) allow reaching such high phosphorus contents.

The difference in phosphorus contents between these methods is not due to a difference in FR diffusion into elementary fibers. In all cases FR diffuses into fiber bulk. The low phosphorus content grafted by chemical modification in soft conditions $(0.52 \mathrm{wt} \%$ at best) is due to the preferential reactivity of phosphonic acid functions towards lignin which is present at low content in flax fibers. Higher phosphorus content may be grafted in severe conditions. But a treatment in these conditions is very degrading for flax.

This study confirms that radiation grafting is more suitable for lowlignin or lignin-free fibers as flax, cotton or hemp than chemical modification in both conditions.

This study also confirms that the thermal stability and flammability of flax fabrics is mainly driven by the phosphorus content. Char residue, thermal stability and self-extinguishing are dependent on phosphorus content.

\section{Appendix A. Supplementary data}

Supplementary data related to this article can be found at http://dx. doi.org/10.1016/j.polymdegradstab.2017.11.006.

\section{References}

[1] M. Zimniewska, M. Wladyka-Przybylak, Natural Fibers for Composite Applications, in: S. Rana, R. Fangueiro (Eds.), Springer Singapore, Singapore, 2016, pp. 171-204.

[2] O. Faruk, A.K. Bledzki, H. Fink, M. Sain, Biocomposites reinforced with natural fibers: 2000-2010, Prog. Polym. Sci. 37 (11) (2012) 1552-1596.

[3] D. Puglia, J. Biagiotti, J.M. Kenny, A review on natural fibre-based composites-Part II: application of natural reinforcements in composite materials for automotive industry, J. Nat. Fibers 1 (3) (2005) 23-65.

[4] J. Biagiotti, D. Puglia, J.M. Kenny, A review on natural fibre-based composites-part I: structure, processing and properties of vegetable fibres, J. Nat. Fibers 1 (2) (2004) 37-68.

[5] L. Yan, B. Kasal, L. Huang, A review of recent research on the use of cellulosic fibres, their fibre fabric reinforced cementitious, geo-polymer and polymer composites in 
civil engineering, Compos. Part B Eng. 92 (2016) 94-132.

[6] S. Hokkanen, A. Bhatnagar, M. Sillanpää, A review on modification methods to cellulose-based adsorbents to improve adsorption capacity, Water Res. 91 (2016) 156-173.

[7] R. Mahjoub, J.M. Yatim, A.R. Mohd Sam, S.H. Hashemi, Tensile properties of kenaf fiber due to various conditions of chemical fiber surface modifications, Constr. Build. Mater. 55 (2014) 103-113.

[8] X. Li, L.G. Tabil, S. Panigrahi, Chemical treatments of natural fiber for use in natural fiber-reinforced composites: a review, J. Polym. Environ. 15 (1) (2007) 25-33.

[9] M. Radetić, Functionalization of textile materials with TiO2 nanoparticles, J. Photochem. Photobiol. C Photochem. Rev. 16 (2013) 62-76.

[10] V.K. Thakur, M.K. Thakur, R.K. Gupta, Graft copolymers of natural fibers for green composites, Carbohydr. Polym. 104 (1) (2014) 87-93.

[11] S. Chapple, R. Anandjiwala, Flammability of natural fiber-reinforced composites and strategies for fire retardancy: a review, J. Thermoplast. Compos. Mater. 23 (6) (2010) 871-893.

[12] Y. Xie, C.A.S. Hill, Z. Xiao, H. Militz, C. Mai, Silane coupling agents used for natural fiber/polymer composites: a review, Compos. Part A Appl. Sci. Manuf. 41 (7) (2010) 806-819.

[13] V. Singh, P. Kumar, R. Sanghi, Use of microwave irradiation in the grafting modification of the polysaccharides - a review, Prog. Polym. Sci. Oxf. 37 (2) (2012) 340-364.

[14] M. John, S. Thomas, Biofibres and biocomposites, Carbohydr. Polym. 71 (3) (2008) 343-364.

[15] M.M. Kabir, H. Wang, K.T. Lau, F. Cardona, Chemical treatments on plant-based natural fibre reinforced polymer composites: an overview, Compos. Part B Eng. 43 (7) (2012) 2883-2892

[16] F. Khan, Characterization of methyl methacrylate grafting onto preirradiated biodegradable lignocellulose fiber by $\gamma$-radiation, Macromol. Biosci. 5 (1) (2005) 78-89.

[17] R. Sonnier, B. Otazaghine, A. Viretto, G. Apolinario, P. Ienny, Improving the flame retardancy of flax fabrics by radiation grafting of phosphorus compounds, Eur. Polym. J. 68 (2015) 313-325.

[18] J.A. Harris, J.C. Arthur, W.R. Goynes, Flame resistant cotton fabrics prepared by radiation-initiated polymerization with vinyl phosphonate oligomer and N-methylolacrylamide, J. Appl. Polym. Sci. 23 (9) (1979) 2555-2565.

[19] J. Gassan, V.S. Gutowski, Effects of corona discharge and UV treatment on the properties of jute-fibre expoxy composites, Compos. Sci. Technol. 60 (15) (2000) 2857-2863.

[20] M. Ragoubi, D. Bienaimé, S. Molina, B. George, A. Merlin, Impact of corona treated hemp fibres onto mechanical properties of polypropylene composites made thereof, Industrial Crops Prod. 31 (2) (2010) 344-349.

[21] A. Baltazar-y-Jimenez, M. Bistritz, E. Schulz, A. Bismarck, Atmospheric air pressure plasma treatment of lignocellulosic fibres: impact on mechanical properties and adhesion to cellulose acetate butyrate, Compos. Sci. Technol. 68 (1) (2008) 215-227.

[22] A. Roy, S. Chakraborty, S.P. Kundu, R.K. Basak, S. Basu Majumder, B. Adhikari, Improvement in mechanical properties of jute fibres through mild alkali treatment as demonstrated by utilisation of the Weibull distribution model, Bioresour. Technol. 107 (2012) 222-228.

[23] P. Saha, S. Manna, S.R. Chowdhury, R. Sen, D. Roy, B. Adhikari, Enhancement of tensile strength of lignocellulosic jute fibers by alkali-steam treatment, Bioresour.
Technol. 101 (9) (2010) 3182-3187.

[24] H.P.S.A. Khalil, H.D. Rozman, M.N. Ahmad, H. Ismail, Acetylated plant-fiber-reinforced polyester composites: a study of mechanical, hygrothermal, and aging characteristics, Polymer-Plastics Technol. Eng. 39 (4) (2000) 757-781.

[25] S.Y. Lu, I. Hamerton, Recent developments in the chemistry of halogen-free flame retardant polymers, Prog. Polym. Sci. Oxf. 27 (8) (2002) 1661-1712.

[26] M.E. Mngomezulu, M.J. John, V. Jacobs, A.S. Luyt, Review on flammability of biofibres and biocomposites, Carbohydr. Polym. 111 (2014) 149-182.

[27] G. Dorez, B. Otazaghine, A. Taguet, L. Ferry, J. Lopez-Cuesta, Improvement of the fire behavior of poly (1, 4-butanediol succinate)/flax biocomposites by fiber surface modification with phosphorus compounds: molecular versus macromolecular strategy, Polym. Int. 63 (9) (2014) 1665-1673.

[28] G. Dorez, B. Otazaghine, A. Taguet, L. Ferry, J.M. Lopez-Cuesta, Use of Py-GC/MS and PCFC to characterize the surface modification of flax fibres, J. Anal. Appl. Pyrolysis 105 (2014) 122-130.

[29] G. Dorez, A. Taguet, L. Ferry, J.-M. Lopez Cuesta, Phosphorous compounds as flame retardants for polybutylene succinate/flax biocomposite: additive versus reactive route, Polym. Degrad. Stab. 102 (2014) 152-159.

[30] B. Szolnoki, et al., Development of natural fibre reinforced flame retarded epoxy resin composites, Polym. Degrad. Stab. 119 (2015) 68-76.

[31] L. Shumao, R. Jie, Y. Hua, Y. Tao, Y. Weizhong, Influence of ammonium polyphosphate on the flame retardancy and mechanical properties of ramie fiber-reinforced poly(lactic acid) biocomposites, Polym. Int. 59 (2) (2010) 242-248.

[32] S. Du, X. Lin, R. Jian, Flame-retardant wrapped ramie fibers towards suppressing 'candlewick effect' of polypropylene/ramie fiber composites, Chin. J. Polym. Sci. 33 (1) (2015) 84-94.

[33] S. Liodakis, I.K. Fetsis, I.P. Agiovlasitis, The fire-retarding effect of inorganic phosphorus compounds on the combustion of cellulosic materials, J. Therm. Analysis Calorim. 98 (1) (2009) 285-291.

[34] R. Sonnier, A. Taguet, L. Ferry, J.-M. Lopez-Cuesta, Towards Bio-based Flame Retardant Polymers, Springer, 2017.

[35] N.P.G. Suardana, M.S. Ku, J.K. Lim, Effects of diammonium phosphate on the flammability and mechanical properties of bio-composites, Mater. Des. 32 (4) (2011) 1990-1999.

[36] M. Parvinzadeh Gashti, A. Almasian, UV radiation induced flame retardant cellulose fiber by using polyvinylphosphonic acid/carbon nanotube composite coating, Compos. Part B Eng. 45 (1) (2013) 282-289.

[37] A.R. Horrocks, S. Zhang, Enhancing polymer char formation by reaction with phosphorylated polyols. 1. Cellulose, Polymer 42 (2001) 8025-8033.

[38] K. Opwis, A. Wego, T. Bahners, E. Schollmeyer, Permanent flame retardant finishing of textile materials by a photochemical immobilization of vinyl phosphonic acid, Polym. Degrad. Stab. 96 (3) (2011) 393-395.

[39] C. Huggett, Estimation of rate of heat release by means of oxygen consumption measurements, Fire Mater. 4 (2) (1980) 61-65.

[40] F. Yao, Q. Wu, D. Zhou, Thermal decomposition of natural fibers: global kinetic modeling with nonisothermal thermogravimetric analysis, J. Appl. Polym. Sci. 114 (2) (2009) 834-842.

[41] R. Sonnier, L. Ferry, J.-M. Lopez-Cuesta, Flame retardancy of phosphorus-containing polymers, in: S. Monge, G. David (Eds.), Phosphorus-based Polymers. From Synthesis to Applications, 2014, pp. 252-270 Cambridge.

[42] R. Sonnier, et al., Studying the thermo-oxidative stability of chars using pyrolysiscombustion flow calorimetry, Polym. Degrad. Stab. 134 (2016) 340-348. 